\title{
Wind Tunnel Experiments for Supersonic Optical-electrical Seeker's Dome Design
}

\author{
Qun Wei, Hongguang Jia, Ming Xuan and Zhenhai Jiang \\ Changchun Institute of Optics, Fine Mechanics and Physics
}

China

\section{Introduction}

Missiles play a more and more important role in the modern wars. The seeker is the most important sub-system of a guided missile. As long as the development of optics, most missiles use optical-electrical seekers. This kind of seeker has plenty of benefits such as high resolving power, anti-camouflage and low cost. Optical guided missile has a optical dome which plays a very important role on the seeker system. The seeker's dome has two jobs: first, it is the first element of the imaging system, so the dome should have good optical performance; second, it protects the sensitive optical, detector, and processor components of the missile seeker from hostile environments such as rain, sand, or large temperature gradients. When missile flies at supersonic, the aero load has serious impacts on seeker's dome. These loads mainly include aerodynamic, aero-thermodynamic, turbulence around the dome and aero vibration. The aerodynamic and aero-thermodynamic make the dome's shape change. The aero-thermodynamic causes heat barrier. And the turbulences and aero vibration make the image dithering and blur. Because all of the above effects are important for dome design, the study of this chapter is necessary. The study of domes has begun for many years, scientists got a lot of achievement in this field. The research is mainly divided into three parts: materials and fabrication[1,2], test and measurement[3,4], aerodynamic and aerothermal[5,6]. For recent years, there is a new branch of optics : conformal optics[7]. Conformal optical systems are characterized as having external optical surfaces that are optimized for non-optical system requirements. This typically implies blending smoothly with a host platform to achieve an optimum shape. Although the open literature provides extensive discussions on current developments in conformal system design, little information is available to study the conformal seeker's dome wind tunnel experiments.

This chapter describes a method for researching the supersonic dome's aero-optical phenomena and theirs influents on optical image by wind tunnel experiments. Combined with thrice wind tunnel experiments and CFD (computational fluid dynamics) numerical simulation, this chapter studies the aerodynamic, aero-thermodynamic and the turbulent of the dome's out surface when it flies at supersonic speed. Then, by using the wind tunnel experiments results, the seeker's image which is affected by missile flies at supersonic speed is studied. After analyzing the results, the conclusion will be the fundamentals to design future domes. The straight matter describes the methods of wind tunnel experiments, and it is divided into three parts. 
Part one: simulated spherical dome wind tunnel experiment study. Most traditional seeker's dome's shape is spherical, so we study its aero-optical effects by wind tunnel experiment first. A model with spherical dome is designed for CFD simulation. After the CFD simulation, all kinds of parameters such as the dome's surface pressure and temperature field are got. Using these results, we analyze their influents on seeker's imaging. Then, the wind tunnel model is made with the same shape of the CFD simulation model. The wind tunnel experiment is done with this model at different kinds of speed and attack angles. After the experiment, actual pressure field of the dome's surface and schieren photography around the dome are got. Comparing the wind tunnel results and the simulation results, the veracity of the simulation is $90 \%$ at average. These two kinds of results are all used to analyze seeker's image influenced by aero-optical phenomena.

Part two: simulated conformal dome wind tunnel experiments study. Along with the development of optical design, optical fabrication and optical test technologies, the new conformal dome will be instead of the traditional spherical dome. This part will study the conformal dome's aero-optical effects caused by missile flies at supersonic speed, and its influences on seeker's image. A model for both CFD simulation and wind tunnel experiments used is designed. The CFD simulation is as same as what have done in part one. The simulation results are prepared for further use. The wind tunnel experiments are done at another wind tunnel. This wind tunnel has bigger experiment part then the one used in part one. Besides that, the wind tunnel models are different too. One model is designed for dome's surface pressure field along with time test experiments, and the other one is designed for dome's surface temperature field along with time test experiments. Wind tunnel experiments are done with different speed and attack angles for both models. The results together with the simulation results got before are used for coupling simulation FEA software. After analyzing and computing, the conformal dome's aero-optical effects are studied, and based on that the $\mathrm{MgF}_{2}$ dome and the seeker shell are designed.

The last part of this chapter is conclusion, and some discussion about future dome design.

\section{Simulated spherical dome wind tunnel experiments study}

Most optical guided missiles use spherical domes, so the first wind tunnel experiment is about spherical dome. The purpose of this wind tunnel experiment is to value the veracity of CFD simulation compared with wind tunnel experiments and to find a way to analysis how the shock wave affect the seeker's dome and optical system.

\subsection{Model definition}

The model of CFD and wind tunnel should be the same, and for this study dome is the only one who will be studied. So the model is designed like below. The model is composed by

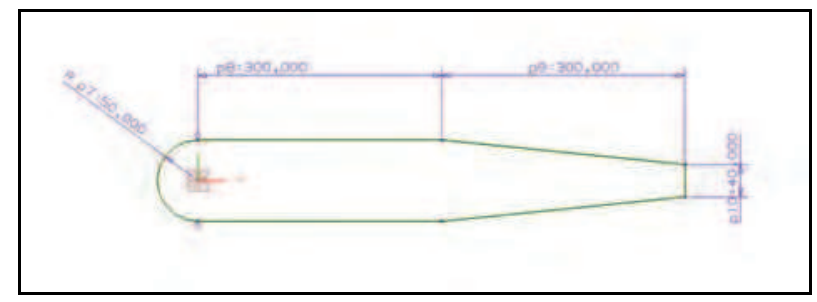

Fig. 1. CFD simulation model 
three parts. The first part is half of a spherical, and the diameter of the spherical is $100 \mathrm{~mm}$. The second part is a column, and its diameter is $100 \mathrm{~mm}$ with a length of $300 \mathrm{~mm}$. The last part is a round platform. The model is shown in figure 1 . The first part is the simulated dome, and the last two parts represent body. The wind tunnel model is made by $30 \mathrm{CrMnSiA}$ as in figure 2 .

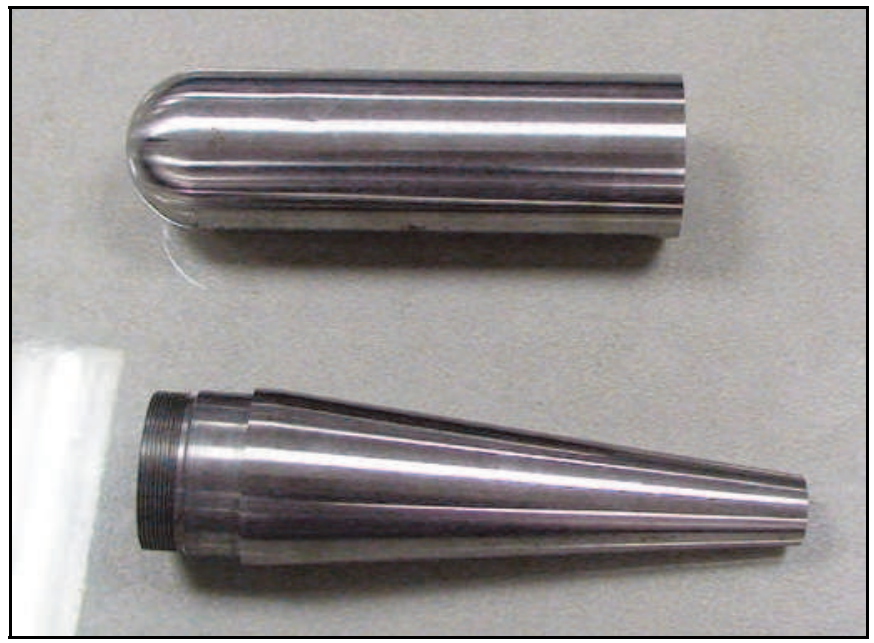

Fig. 2. Wind tunnel model

\subsection{Grid generation}

The first step to build the grid is to define the outflow area of the model. The outflow figure is shown in figure 3.

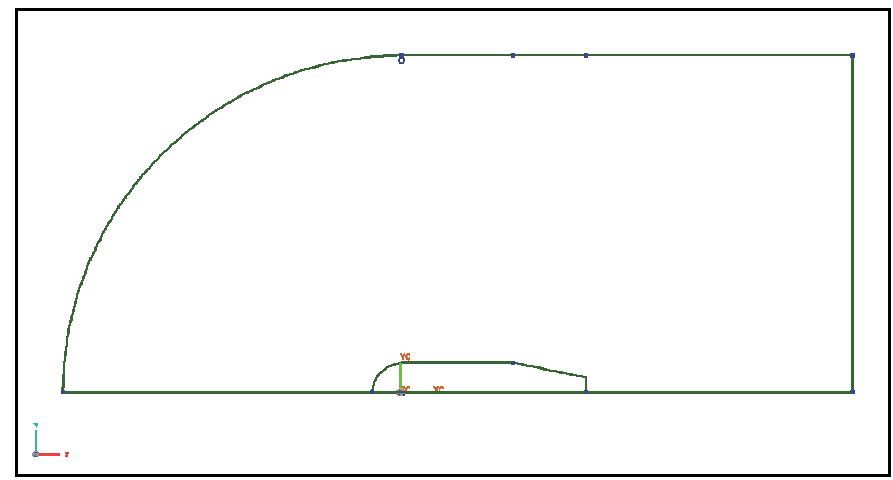

Fig. 3. The outflow of the dome

For compare, there are four kinds of grid used in this simulation. First, the structure grid is used for the dome's grid as in figure 4 . The black part is the dome and the body. The yellow grid is symmetry boundary, and the red grid is outflow. And the un-structure gird, mix grid and polyhedra grid are shown in figure 5 figure 6 and figure 7. 


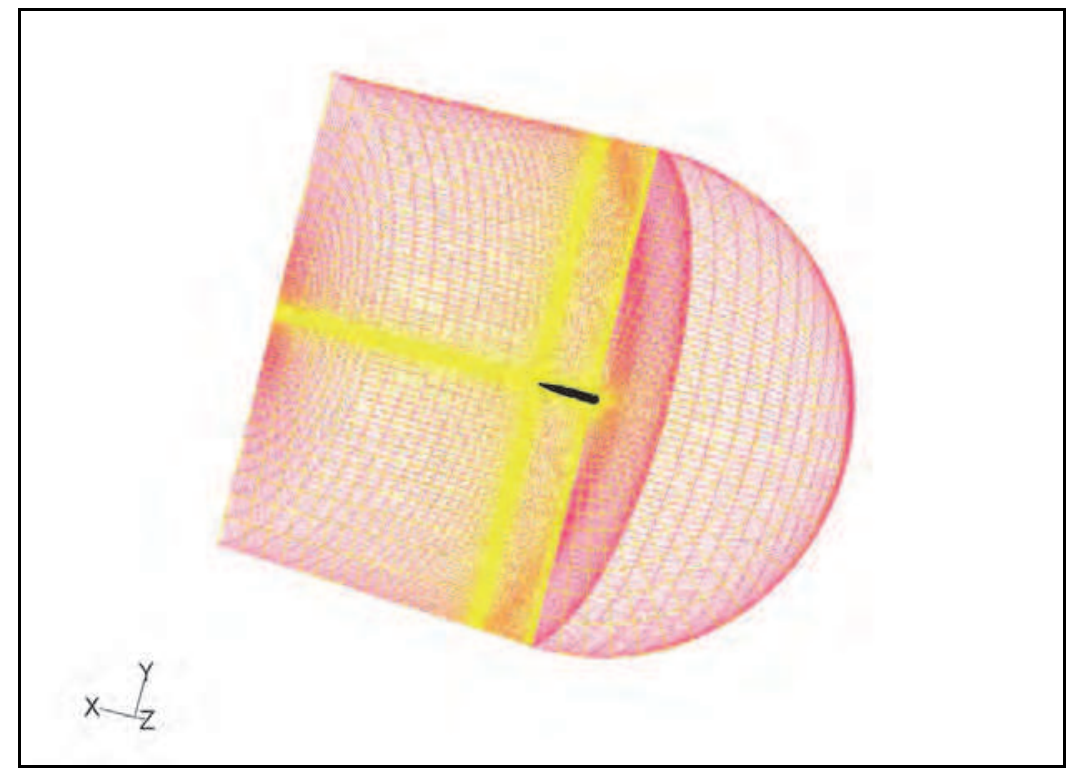

Fig. 4. Grid of the simulation dome outflow

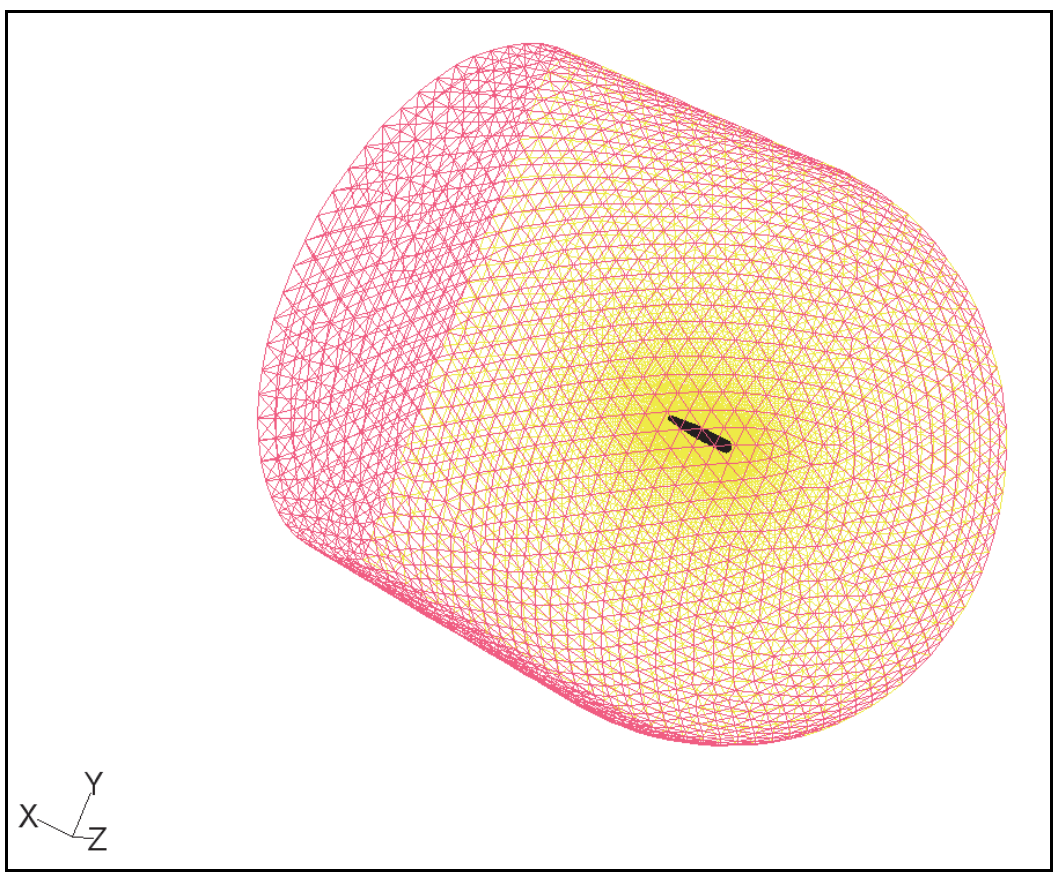

Fig. 5. Un-structure grid 


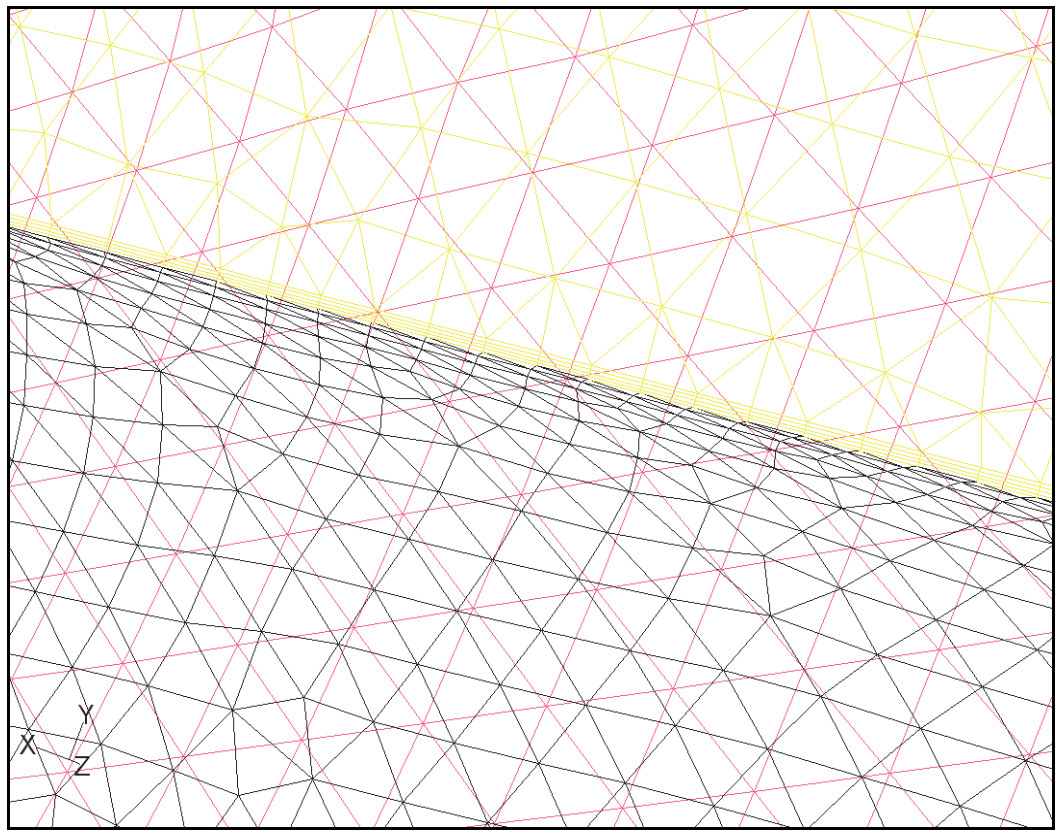

Fig. 6. Mix grid

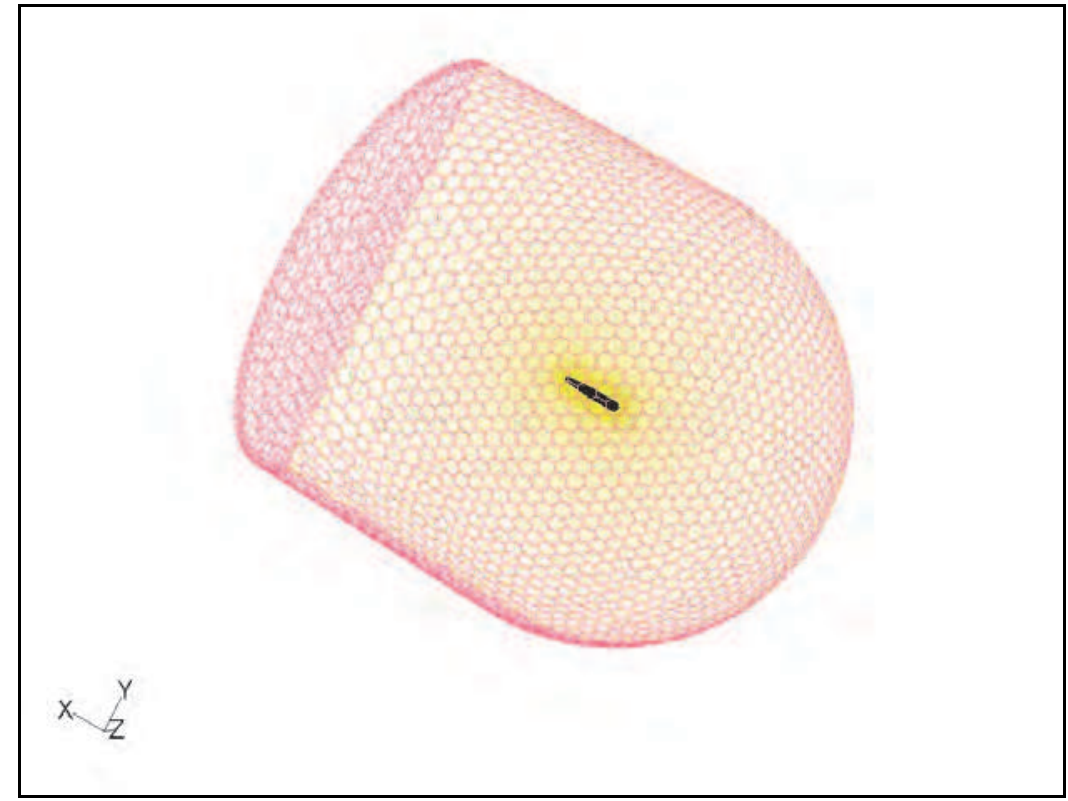

Fig. 7. Polyhedra grid 


\subsection{CFD setup}

The flow solver uses a finite-volume technique with multi-zone method to solve multidimensional flow in a body-fitted grid system[8]. The blending of density- and pressurebased numerical methodology in the code allows efficient computation of compressible flow regimes. For turbulent flow computations, the Partially-Average Navier-Stokes (PANS) technique was implemented in the $\mathrm{k}-\varepsilon$ model[$[9,10]$.

\subsection{Wind tunnel experiment}

The wind tunnel experiment is done in trisonic wind tunnel of China Academy of Aerospace and Aerodynamics (CAAA). This wind tunnel is an intermittent semireturn type with Mach number ranging from 0.4 to 4.5 . The cross area of the test section is $0.6 \mathrm{~m} \times 0.6 \mathrm{~m}$ and the length is $1.575 \mathrm{~m}$. The flow quality in the wind tunnel is satisfactory and completely up to the national standards of high speed wind tunnel. This tunnel has steady performance characters[11]. The experiment is shown in figure 8. The model is fixed on the "forcebalance" and can be seen though the view window.

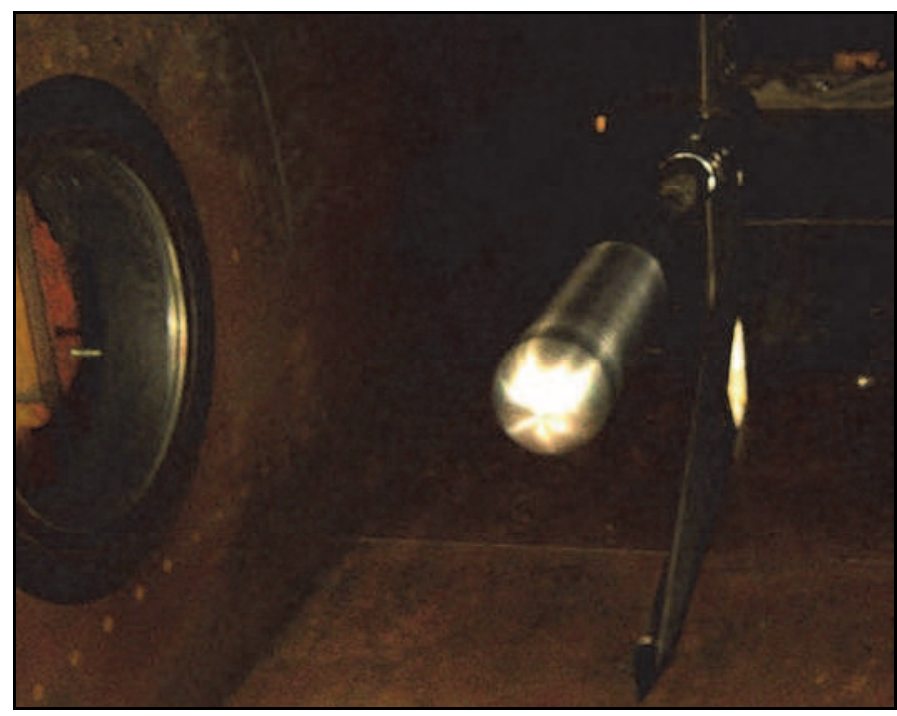

Fig. 8. Spherical dome wind tunnel experiment

\subsection{Results}

\subsection{1 wind tunnel experiment data processing and precision}

On the assumption that the air flow from front area to experiment area is isentropic process. So the total pressure and total temperature of experiment area are equal to front area. The effects of the wind tunnel model and balance's self weigh has been modified. The RMS random error is shown in table 1.

\subsubsection{Wind tunnel results and analysis}

As the data of the wind tunnel experiments are a great many, the data is shown in figures. Normal force coefficient with attack angle is shown in figure 9. 


\begin{tabular}{|c|c|c|c|}
\hline$\varepsilon_{\alpha}$ & $\varepsilon_{c n}$ & $\varepsilon_{c a f}$ & $\varepsilon_{c a b}$ \\
\hline $\pm 0.02^{\circ}$ & \pm 0.0010 & \pm 0.0050 & \pm 0.0060 \\
\hline$\varepsilon_{C z}$ & $\varepsilon_{m z 0}$ & $\varepsilon_{m y 0}$ & $\varepsilon_{m x}$ \\
\hline \pm 0.0020 & \pm 0.0005 & \pm 0.0005 & \pm 0.0004 \\
\hline
\end{tabular}

Table 1. RMS random error

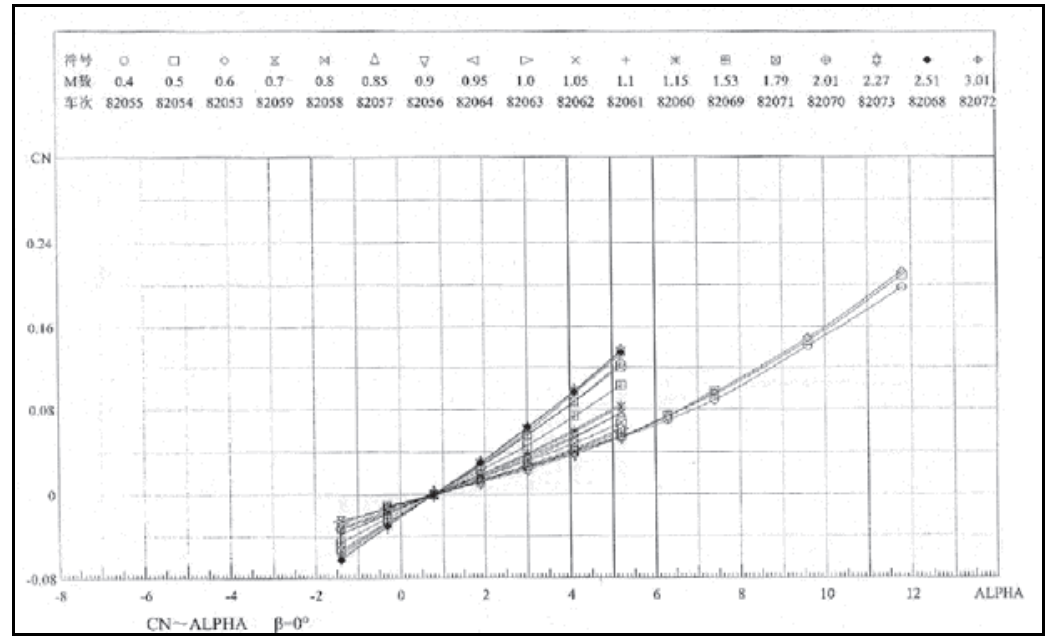

Fig. 9. Normal force coefficient with attack angle

Normal force coefficient with Mach number is shown in figure 10.

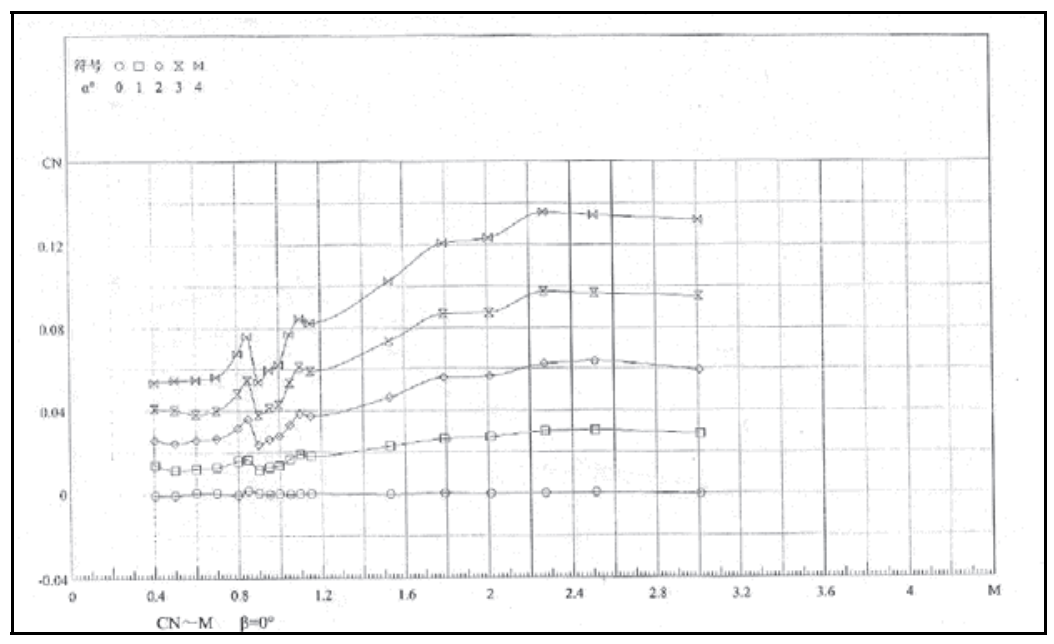

Fig. 10. Normal force coefficient with Mach number 
Lengthwise pressure centre coefficient is shown in figure 11.

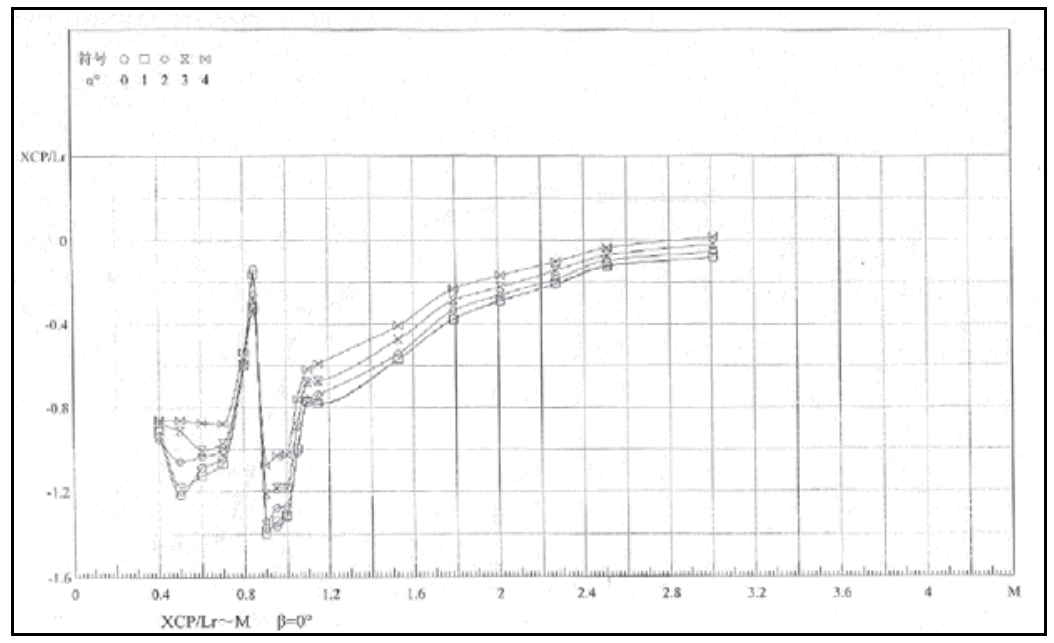

Fig. 11. Lengthwise pressure centre coefficient

Front axial force coefficient is shown in figure 12.

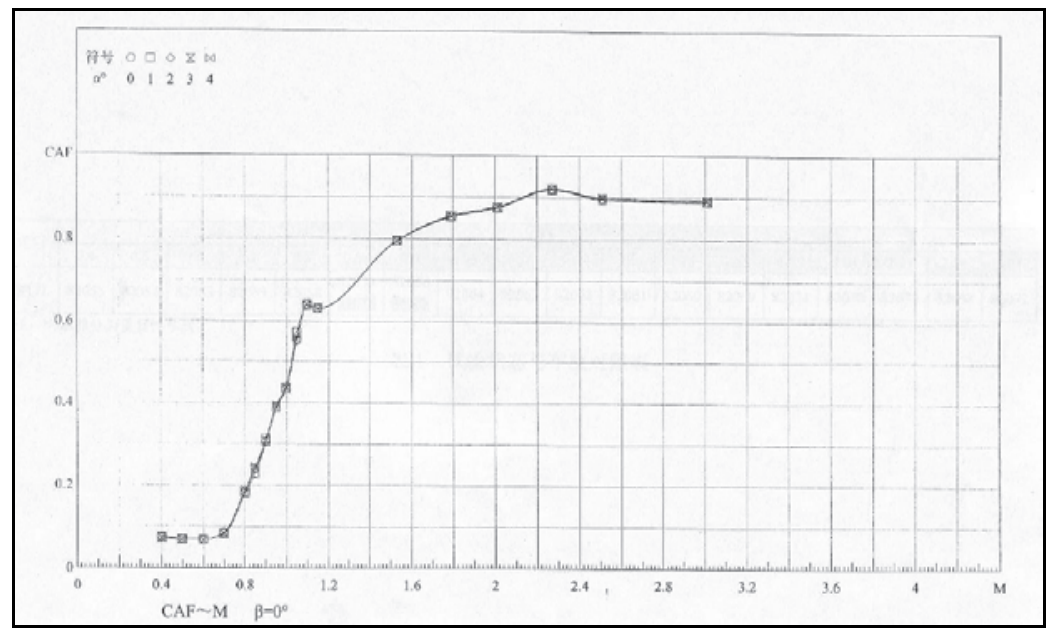

Fig. 12. Front axial force coefficient

\subsubsection{CFD results}

There are four kinds of grid. The first step is to value which kind of grid is more suitable for this dome CFD simulation. The drag comparison table is shown in table 2 .

Compared with the wind tunnel experiments' result, the structire grid is more suitable for this kind of simulation. Then using the structure grid, more CFD simulations have been done. And we can get the precision of CFD simulation. The comparison table is shown in table 3. 


\begin{tabular}{|c|c|c|c|c|c|}
\hline Speed (Ma) & 0.6 & 0.95 & 1.5 & 2 & 2.6 \\
\hline Structure grid & 12.915 & 109.535 & 486.925 & 950.299 & 1625.430 \\
\hline Un-structure grid & 26.973 & 138.798 & 509.046 & 969.552 & 1704.025 \\
\hline Mix grid & 30.069 & 158.682 & 508.339 & 978.657 & 1708.466 \\
\hline Polyhedra grid & 17.373 & 111.899 & 501.365 & 970.484 & 1672.004 \\
\hline
\end{tabular}

Table 2. Drag comparison table

\begin{tabular}{|c|c|c|c|c|}
\hline & & CFD & Wind tunnel & error \\
\hline \multirow{3}{*}{$\begin{array}{c}0.4 \mathrm{Ma} \\
4^{\circ}\end{array}$} & Drag & 74.6 & 70.5 & $5 \%$ \\
\hline & Lift & 289.9 & 272.3 & $6 \%$ \\
\hline & Pressure centre & 1306 & 1418 & $7.8 \%$ \\
\hline \multirow{3}{*}{$\begin{array}{c}0.6 \mathrm{Ma} \\
6^{\circ}\end{array}$} & Drag & 169.3 & 149.4 & $13 \%$ \\
\hline & Lift & \begin{tabular}{|l|}
1016.6 \\
\end{tabular} & 982.9 & $3.5 \%$ \\
\hline & Pressure centre & 1362 & 1448 & $6 \%$ \\
\hline \multirow{3}{*}{$\begin{array}{c}0.8 \mathrm{Ma} \\
8^{\circ}\end{array}$} & Drag & 308.1 & 272.7 & $13.2 \%$ \\
\hline & Lift & \begin{tabular}{|l|}
2643.2 \\
\end{tabular} & 2569.1 & $2.9 \%$ \\
\hline & Pressure centre & 1526 & 1457 & $4.5 \%$ \\
\hline \multirow{3}{*}{$\begin{array}{c}1.1 \mathrm{Ma} \\
4^{\circ}\end{array}$} & Drag & \begin{tabular}{|l|}
1367.9 \\
\end{tabular} & 1164.5 & $17 \%$ \\
\hline & Lift & \begin{tabular}{|l|}
2815.4 \\
\end{tabular} & 2640.7 & $6 \%$ \\
\hline & Pressure centre & 1561 & 1408 & $10 \%$ \\
\hline \multirow{3}{*}{$\begin{array}{c}1.5 \mathrm{Ma} \\
0^{\circ}\end{array}$} & Drag & \begin{tabular}{|l|}
2619.4 \\
\end{tabular} & 2289.3 & $14 \%$ \\
\hline & Lift & -43 & 0 & - \\
\hline & Pressure centre & 1182 & 1294 & $9 \%$ \\
\hline \multirow{3}{*}{$\begin{array}{c}2 \mathrm{Ma} \\
2^{\circ}\end{array}$} & Drag & \begin{tabular}{|l|}
4349.9 \\
\end{tabular} & 4154.2 & $3.8 \%$ \\
\hline & Lift & \begin{tabular}{|l|}
2198.3 \\
\end{tabular} & 2594.6 & $15 \%$ \\
\hline & Pressure centre & 1528 & 1434 & $6.5 \%$ \\
\hline \multirow{3}{*}{$\begin{array}{c}2.5 \mathrm{Ma} \\
5^{\circ}\end{array}$} & Drag & \begin{tabular}{|l|}
6374.3 \\
\end{tabular} & 6260.2 & $0.98 \%$ \\
\hline & Lift & 8220.2 & 8462.9 & $2.9 \%$ \\
\hline & Pressure centre & 1497 & 1462 & $2.4 \%$ \\
\hline \multirow{3}{*}{$\begin{array}{l}3 \mathrm{Ma} \\
10^{\circ}\end{array}$} & Drag & 8372.5 & 8591.5 & $2.5 \%$ \\
\hline & Lift & 23255.2 & 23469.4 & $0.9 \%$ \\
\hline & Pressure centre & 1529 & 1471 & $3.9 \%$ \\
\hline
\end{tabular}

Table 3. CFD and wind tunnel experiments comparison table

The biggest error is the drag value at Mach 1.1 attack angle $4^{\circ}$, and the best CFD simulation is the lift value at Mach 3 attack angle $10^{\circ}$. The average drag error is $8.685 \%$, the average lift value is $5.314 \%$, and the average pressure centre value is $6.263 \%$. Accoding these results, the CFD simulation is good enough for dome design.

\subsubsection{CFD contours}

In this experiment, the outline of shock wave can be seen clearly, and accurate aero-dynamic force of all kinds of flight condition are obtained. The compare of the shock wave which is shown in Figure 13 can prove the simulation is accurate. After this experiment, the density field of the outflow can be obtained. 


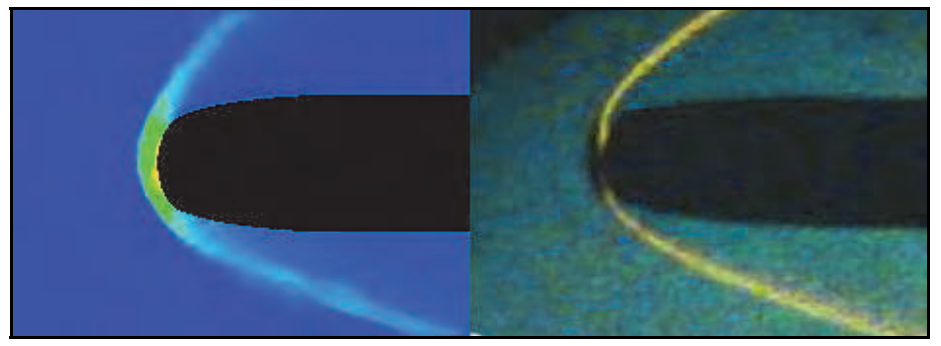

Fig. 13. Shock wave comparison figure

\subsection{Equivalent lens deisign}

The Lorentz-lorenz formula provides a bridge linking Maxwell's electromagnetic theory with the micro substances[11]. The relationship between the flow-field density $\rho$ and the refractive index $n$ is modeled by[12]:

$$
\left(\frac{n^{2}-1}{n^{2}+2}\right) \frac{1}{\rho}=\frac{2}{3} K_{G D}
$$

Here KGD is the G-D constant. Generally, the refractive index of air relies on the density in normal temperature. If the temperature is very high, the index of refraction will be dependent mainly on the temperature and components of fluids. This paper neglects the influences of aerodynamic heating and ionization on the index and considers only the effects of varying flow densities on the refractive index. Because the index of normal airflow is approximately equal to 1 , the G-D relationship can be gained by the following:

$$
n=1+K_{G D} \rho
$$

Where $\rho$ is the local density of outflow, and for visible light KGD is 0.22355 [13]. Using the formula above, the refractive index of the outflow can be obtained accurately. The density field calculated by CFD is discrete, so the refractive index of outflow is discrete too. In that case, the refractive is divided into three zones, and each of them has a equal refractive index. The figure 14 shows the refractive index zones by different colors.

Thought the key points' coordinates, the formulas of the two boundaries can be calculated. Together with the refractive index, the two equivalent lenses are gotten. The inside lens(the red zone in the above figure) has a refractive index of $1.004,52.535702 \mathrm{~mm}$ for radius and its thickness is $2.535702 \mathrm{~mm}$. The outside lens(the yellow zone)'s refractive index is 1.010 with the radius is $57.804844 \mathrm{~mm}$ and the thickness is $5.269142 \mathrm{~mm}$.

\subsection{Conclusions}

In this section, the spherical dome wind tunnel experiments have been done. By comparing the result of CFD simulation and wind tunnel experiments, we can get that the average drag error is $8.685 \%$, the average lift error is $5.314 \%$, and the average pressure centre error is $6.263 \%$. The shock wave figures which are got from wind tunnel experiments and CFD simulation are nearly the same. By using these results, the equivalent lens is designed for missile's dome design. 


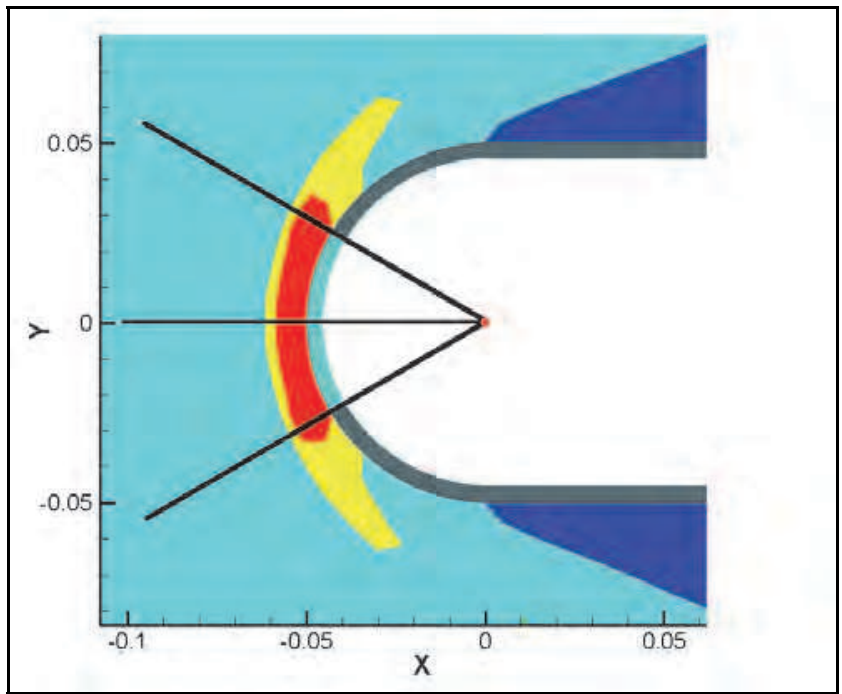

Fig. 14. The refractive index zones. The black lines are line of sight.

\section{Simulated conformal dome wind tunnel experiments study}

\subsection{Backgroud}

Conformal optics systems contain optical components such as windows or domes that a shape which reduces the effect of the atmosphere on system aerodynamic, mechanical, electrical or thermal performance. The most obvious application concept is that of a missile nose cone. Traditional missiles use a flat or spherical window covering an optical tracker or seeker. Neither of these shapes interacts well with the high-speed airflow across the front end of the missile. An optimum shape would be given by a vonkaiman tangent ogive, which provides a minimum drag front end to the airflow. Between the blunt spherical shape and the pointed ogival shape there is a continuum of shapes that permit reduced drag but do produce a range of optical aberration effects that must be compensated by elements following the missile front end window.

The conformal dome has so many benefits, but there are some problem which should be considered first. When the missile flies at supersonic speed, the aerodynamic will make the dome's shape change. Not only must the dome withstand high pressure and forces of hundreds of pounds during the high speed flight of the missile, it must also withstand severe thermal gradients from the increases in temperature at these speeds. The elevated temperatures heat the dome surface while the interior of the dome remains at a lower temperature, which causes thermal stress across the dome interior. The capability of the dome to withstand thermal stress is very important for dome design. So the conformal dome wind tunnel experiments are done to value how the aerodynamic and thermal affect the conformal dome.

\subsection{Wind tunnel experiment model}

The aim of this wind tunnel experiment is not the same as the spherical dome wind tunnel experiments. Differently, the aim of this wind tunnel experiment is to get the pressure and 
temperature of the conformal dome surface. Because the way to measure the pressure and temperature is different, this wind tunnel experiment is divided into two parts. So the first model is design for pressure measurement. The figure of pressure measurement model is shown in figure 15.

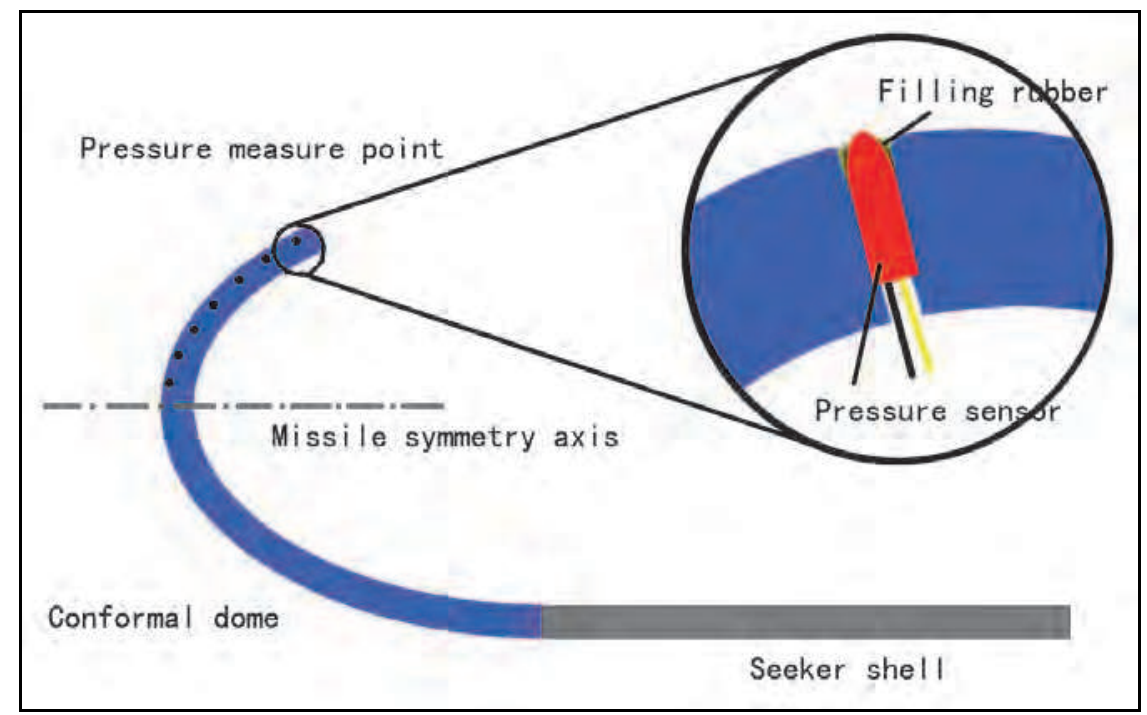

Fig. 15. Pressure measure model figure

The position of the pressure measure point is shown in figure 16.

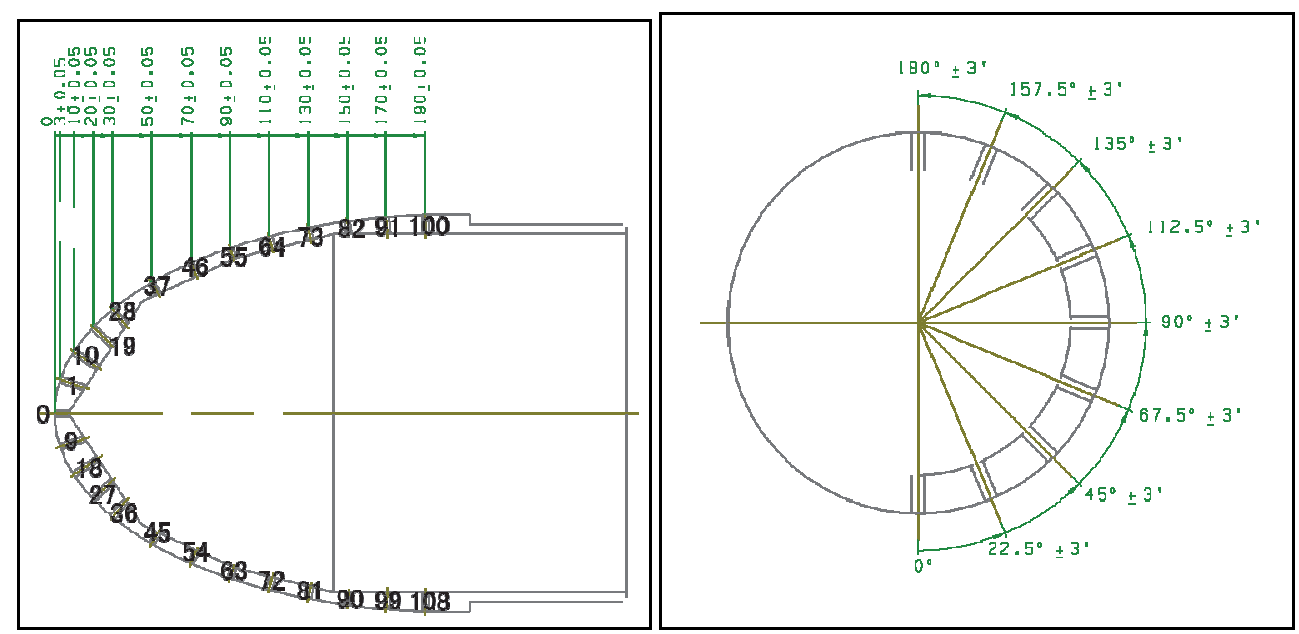

Fig. 16. The position of pressure measure points

The model is designed as above figure, and made by $30 \mathrm{CrMnSiA}$. The wind tunnel model is shown in figure 17. 


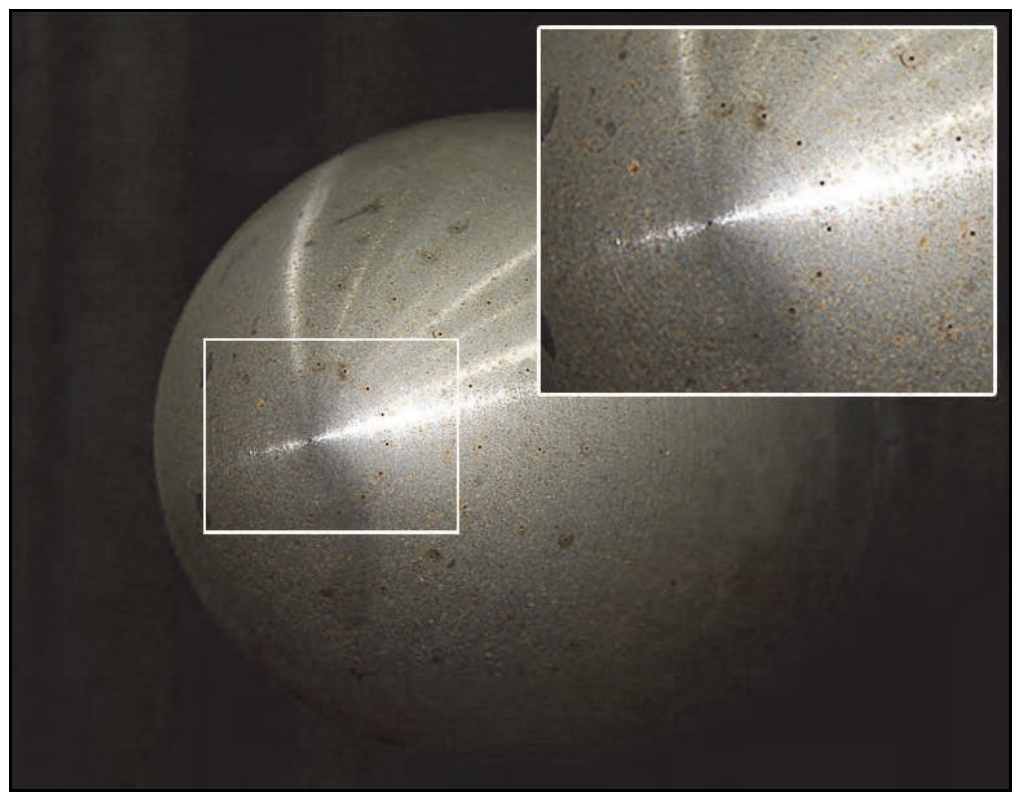

Fig. 17. Pressure measure wind tunnel experiment model

The same as pressure measure model, the temperature measure model is designed as in figure 18 .

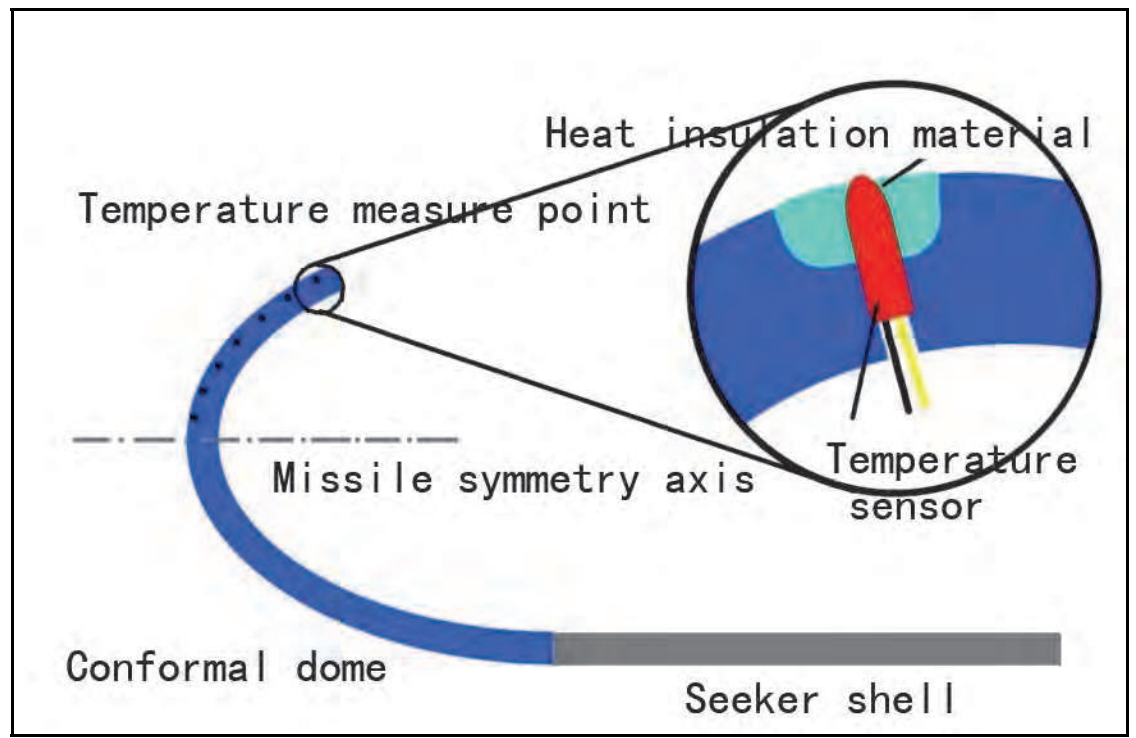

Fig. 18. Temperature measure wind tunnel model

The position of temperature measure point is shown in figure 19. 


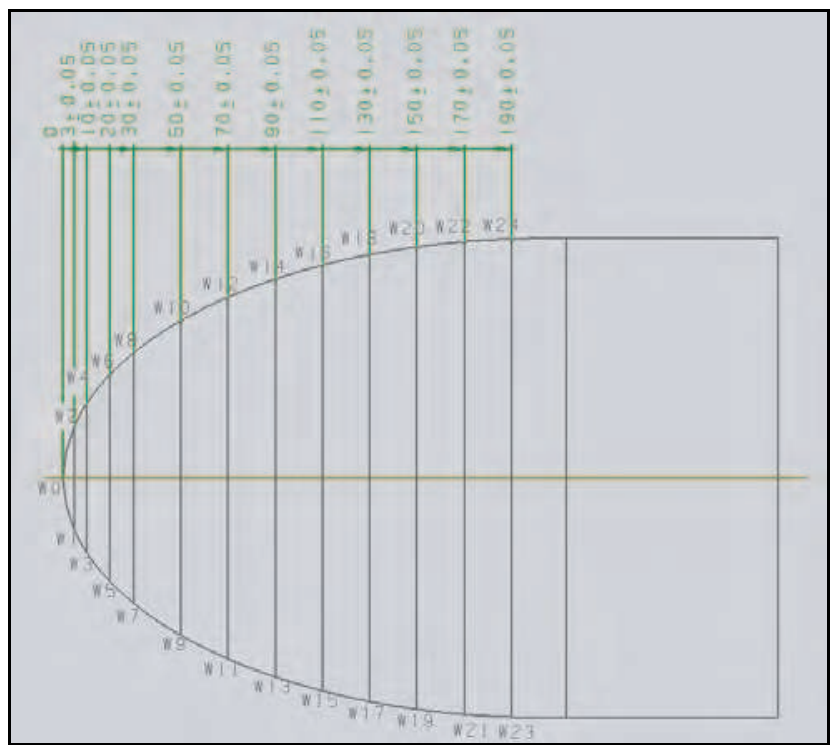

Fig. 19. The position of temperature measure point

The temperature measure wind tunnel experiment model is made by $30 \mathrm{CrMnSiA}$, and shown in figure 20.

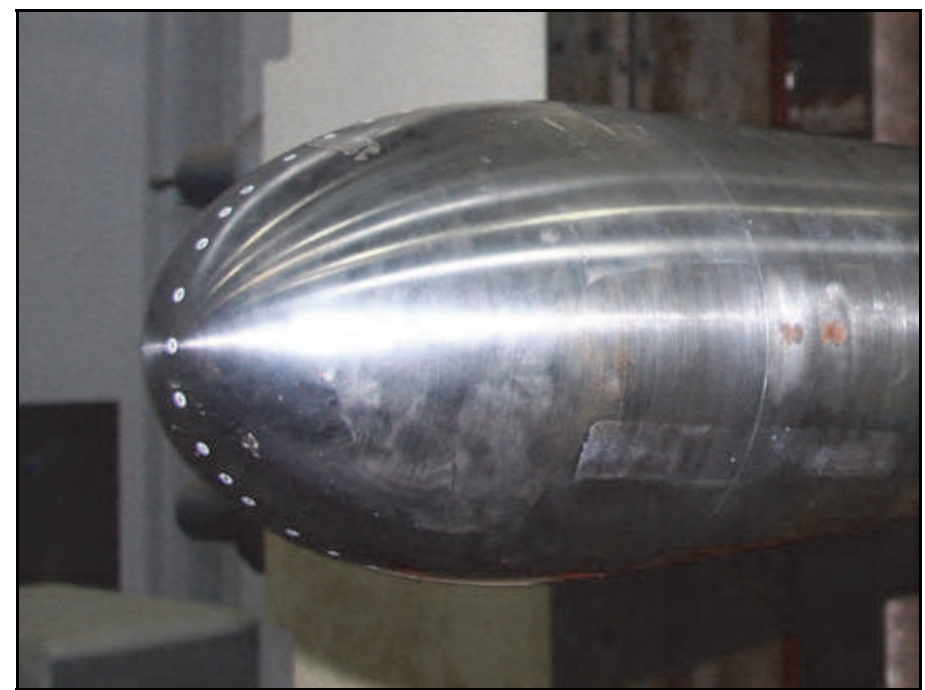

Fig. 20. Temperature measure wind tunnel model

\subsection{CFD model and grid generation}

According to the wind tunnel model above, the CFD model for simulation is designed and shown in figure 21. 


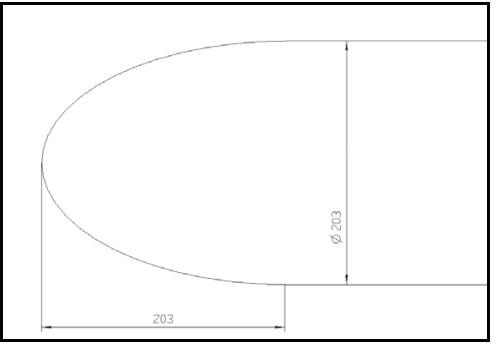

Fig. 21. CFD simulation model

The structure grid generation of the conformal dome surface is shown in figure 22 .

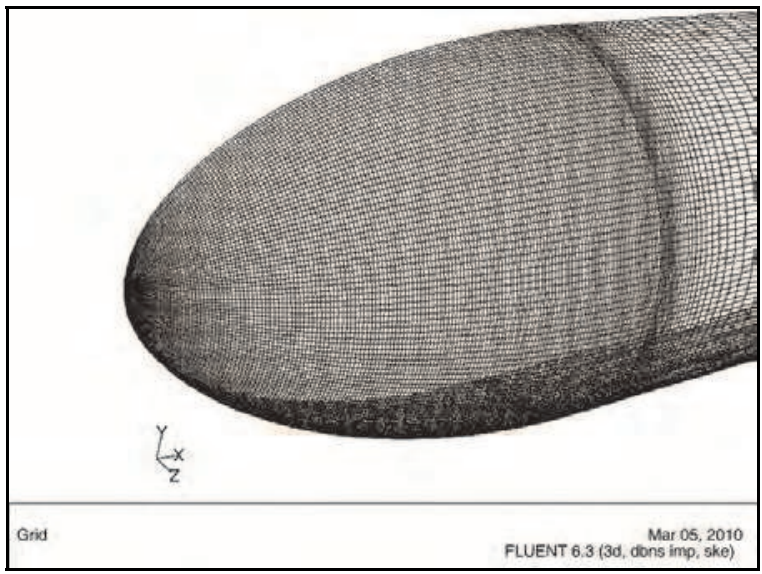

Fig. 22. Conformal dome surface grid

The outflow grid is shown in figure 23.

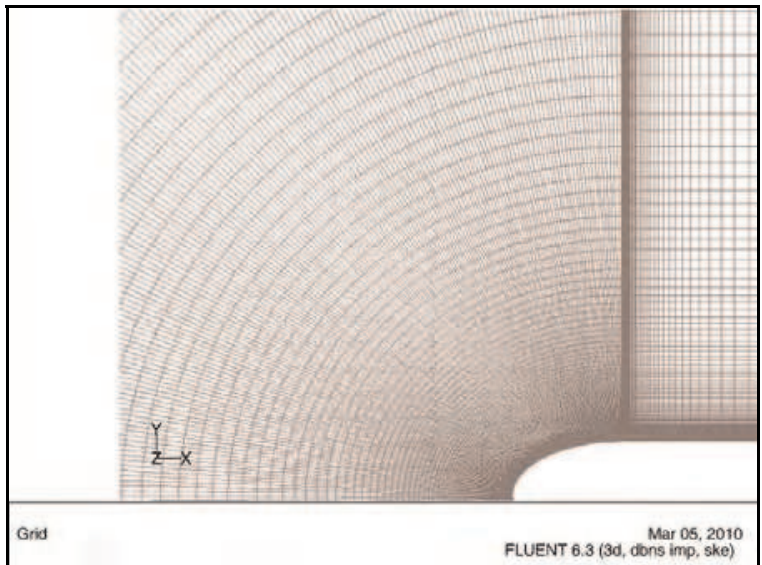

Fig. 23. The outflow grid 


\subsection{Wind tunnel experiments}

\subsubsection{Pressure measure wind tunnel experiment}

This wind tunnel experiment is get the pressure distributing of the conformal dome's surface. The flight condition is according the missile's attacking mission. So the wind tunnel experiments are taken at Mach number 2, 2.5 and 3. The attack angles are $0^{\circ}, 10^{\circ}, 20^{\circ}$ and $25^{\circ}$. The wind tunnel experiment photo is shown in figure 24 .

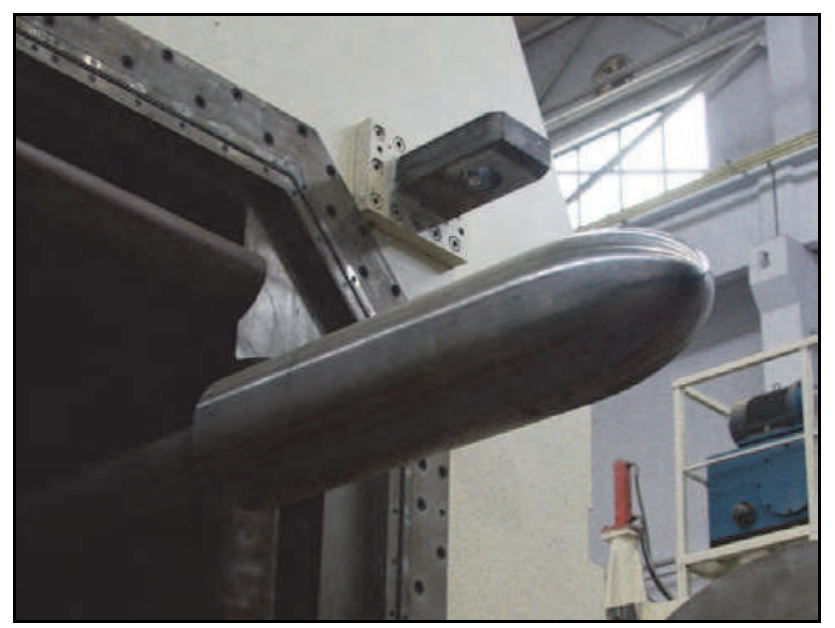

Fig. 24. Pressure measure wind tunnel experiment

\subsubsection{Temperature measure wind tunnel experiment}

Temperature measure wind tunnel experiment is taken as the same condition as the pressure measure wind tunnel experiment. The wind tunnel experiment photo is shown in figure 25 .

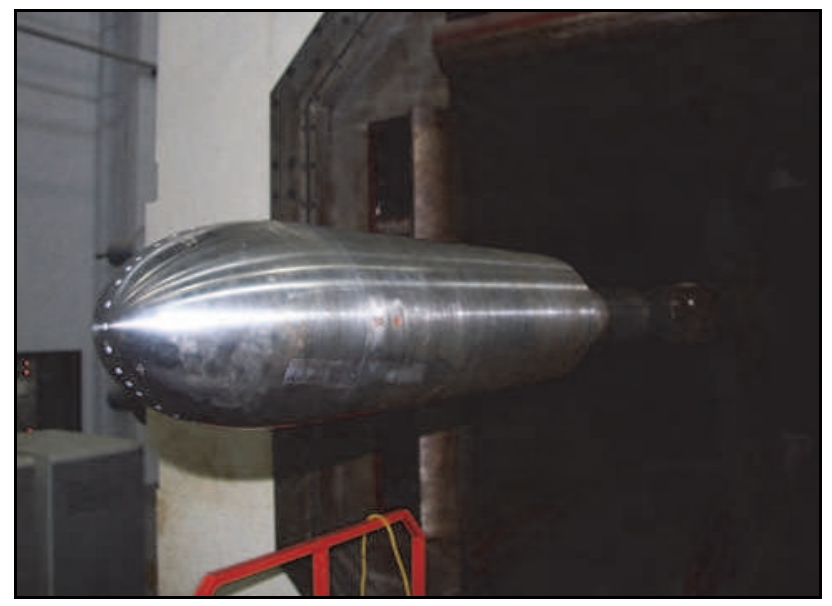

Fig. 25. Temperature measure wind tunnel experiment 


\subsection{Results}

\subsubsection{CFD simulation results}

The pressure data of conformal dome surface will be discussed later together with the real wind tunnel data. The figure of static pressure is shown in figure 26 . The attack angle are $10^{\circ}, 20^{\circ}, 30^{\circ}$ and $40^{\circ}$.

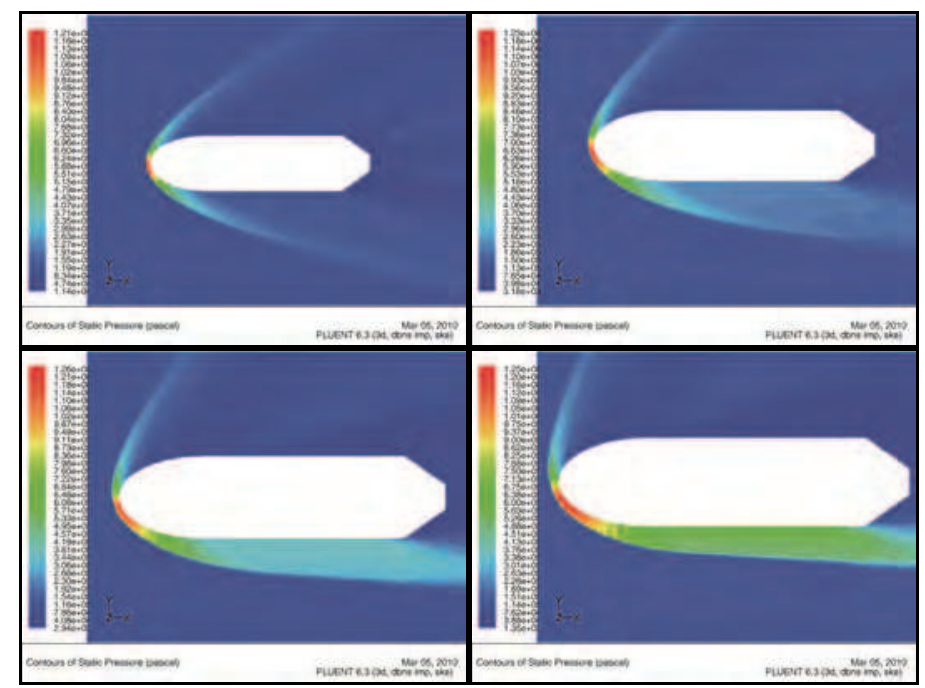

Fig. 26. Static pressure contour

Studying the figure above, it is clearly seen that when missile flies at one speed such as 3Ma the angle between shock wave and the missile body is becoming smaller when the attack angle goes higher. The high pressure zone(the red and orange aera) gets larger. The windward surface and the leeward surface are under different pressure load, so it is very important to consider this uneven force in conformal dome design section.

The static temperature figure is shown in figure 27 . The attack angle is $20^{\circ}$, and the mach number is $2,2.5$, and 3 .

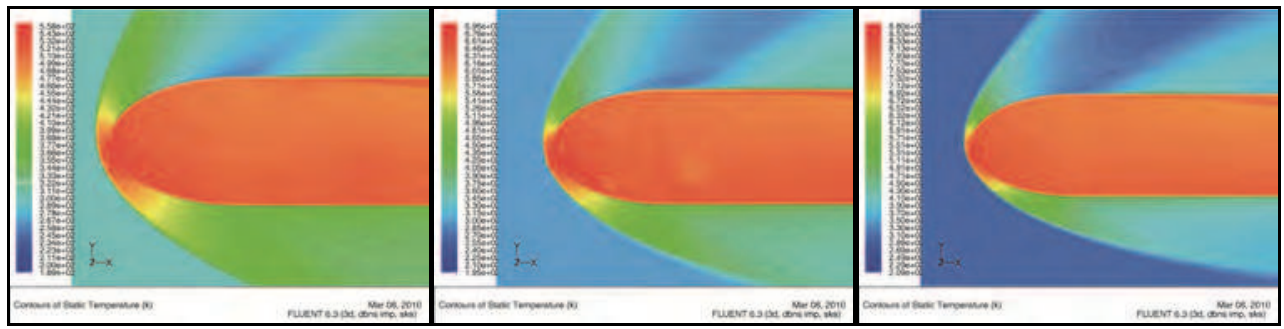

Fig. 27. Static temperature contour

\subsubsection{Wind tunnel results}

The conformal dome surface pressure data of $2 \mathrm{Ma}$ is shown in figure 28 . The attack angles are $0^{\circ}, 10^{\circ}, 20^{\circ}$ and $25^{\circ}$. 

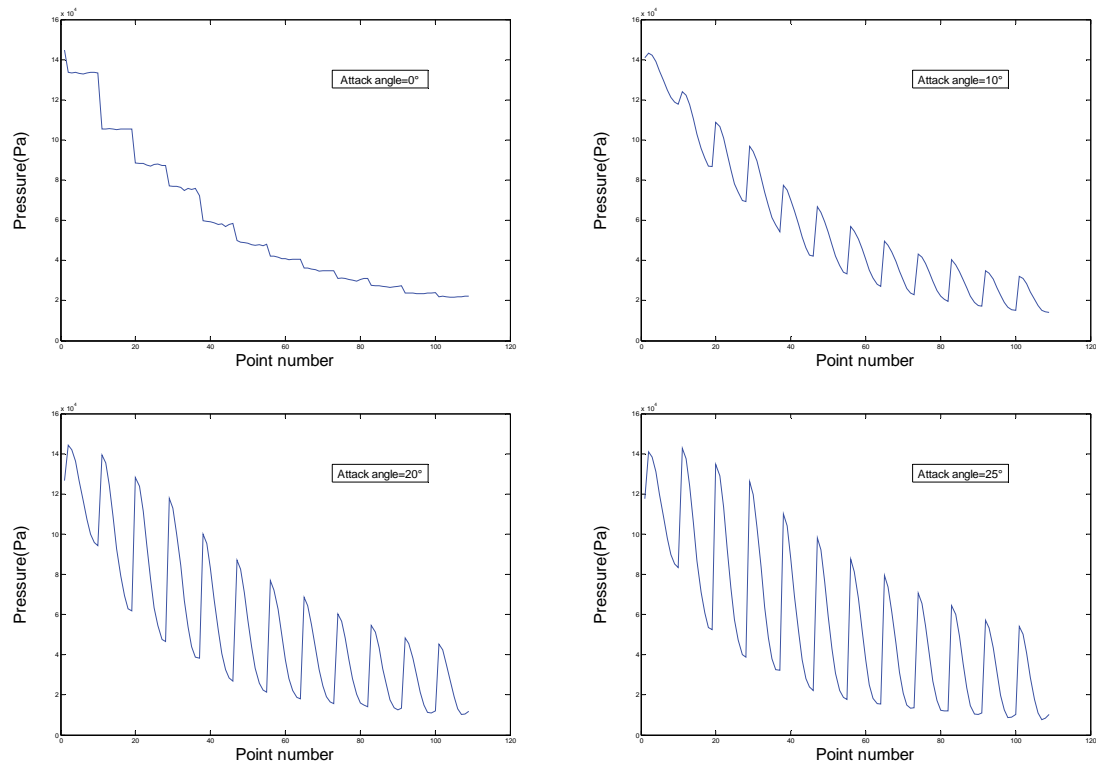

Fig. 28. Conformal dome surface pressure data of $2 \mathrm{Ma}$

The data of $2.5 \mathrm{Ma}$ is shown in figure 29 . The attack angle is the same as $2 \mathrm{Ma}$.
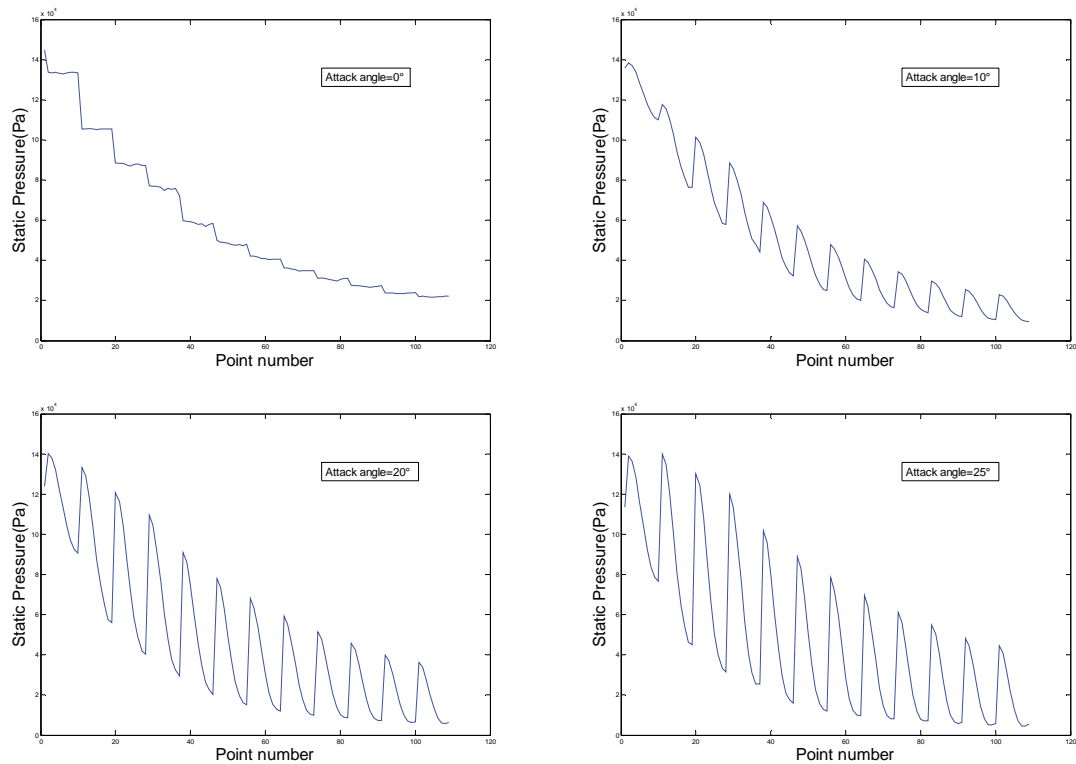

Fig. 29. Conformal dome surface pressure data of $2.5 \mathrm{Ma}$ 
The data of $3 \mathrm{Ma}$ is shown in figure 30.
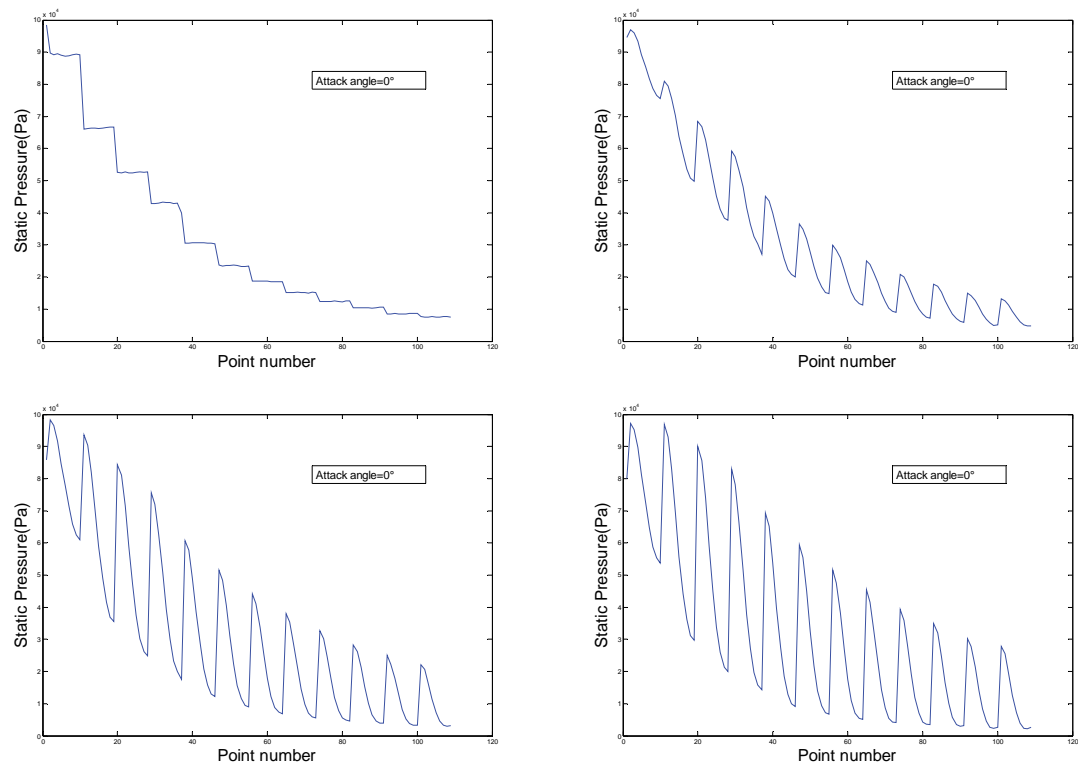

Fig. 30. Conformal dome surface pressure data of $3 \mathrm{Ma}$

The wind tunnel data is used for conformal dome design. The surface pressure is the input parameter of FEA. The surface pressure data is used to calculate the distortion of the conformal dome when it is under great load of outflow. But wind tunnel data can not provide all point value of pressure on the dome's surface. So CFD simulation data is used when the wind tunnel data is not enough. In this situation, the accuracy of CFD simulation becomes significant in this study. In the above part, the accuracy of force is discussed. The pressure of

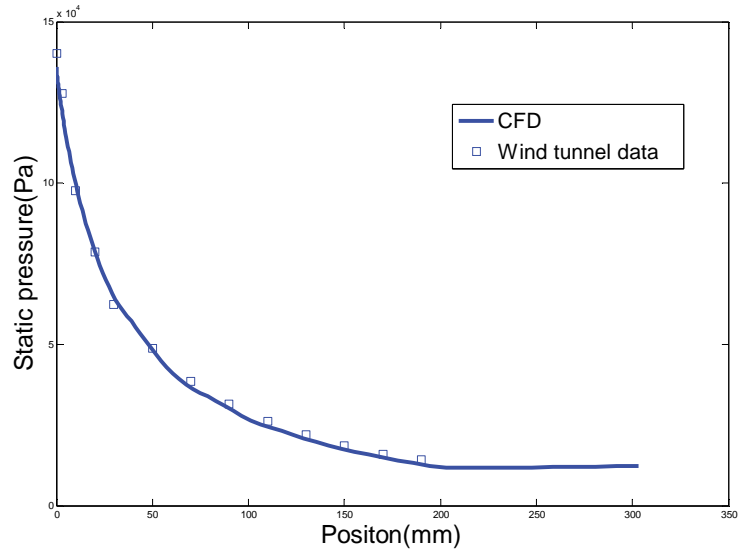

Fig. 31. CFD and wind tunnel data comparison of $2.5 \mathrm{Ma}$ attack angle $0^{\circ}$ 


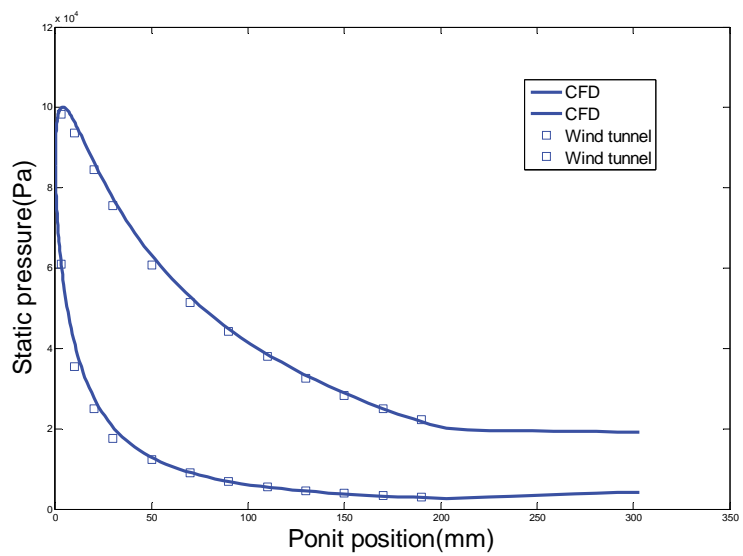

Fig. 32. CFD and wind tunnel data comparison of $3 \mathrm{Ma}$ attack angle $20^{\circ}$

conformal dome's generatrix will be compared to value whether the pressure data of CFD simulation is correct. Figure 31 shows the data of CFD and wind tunnel at 2.5Ma with the attack angle is equal to $0^{\circ}$, and figure 32 showns the comparison of condition $3 \mathrm{Ma} 20^{\circ}$.

From the figures above, it is clearly seen that the wind tunnel data and the CFD simulation data match perfectly. This means that the CFD simulation data can be used for further design. The temperature data of the surface will not be shown here, because the data is processed in the way.

\subsection{Conformal dome analysis}

In the above study, we can get the exact pressure and temperature data of conformal dome's surface from wind tunnel experiments and CFD simulation. This data is used for conformal dome's FEA simulation. The purpose to progressing the FEA simulation is to value how the aerodynamic load and aerothermal affect the conformal dome's performance. The shape of the dome will change when missile flies at different speed and attack angle. The conformal dome's grid is shown in figure 33.

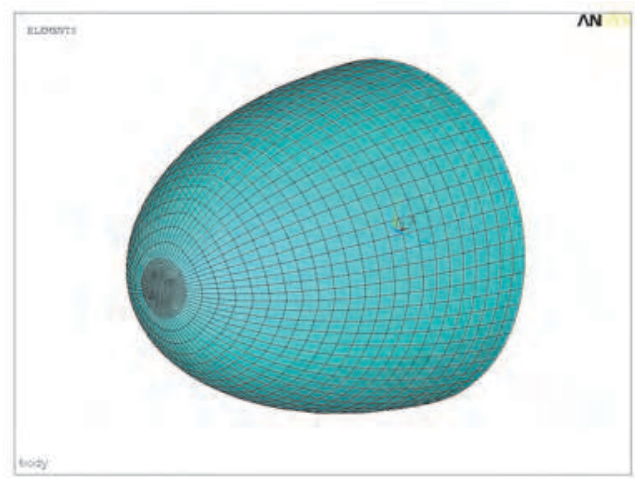

Fig. 33. Conformal dome grid 
The temperature data of the dome's surface is the input file of FEA simulation. The result of conformal dome's temperature distribution is shown in figure 34. In this figure, we can get that along with the speed gets higher, the red area which means high temperature becomes larger.

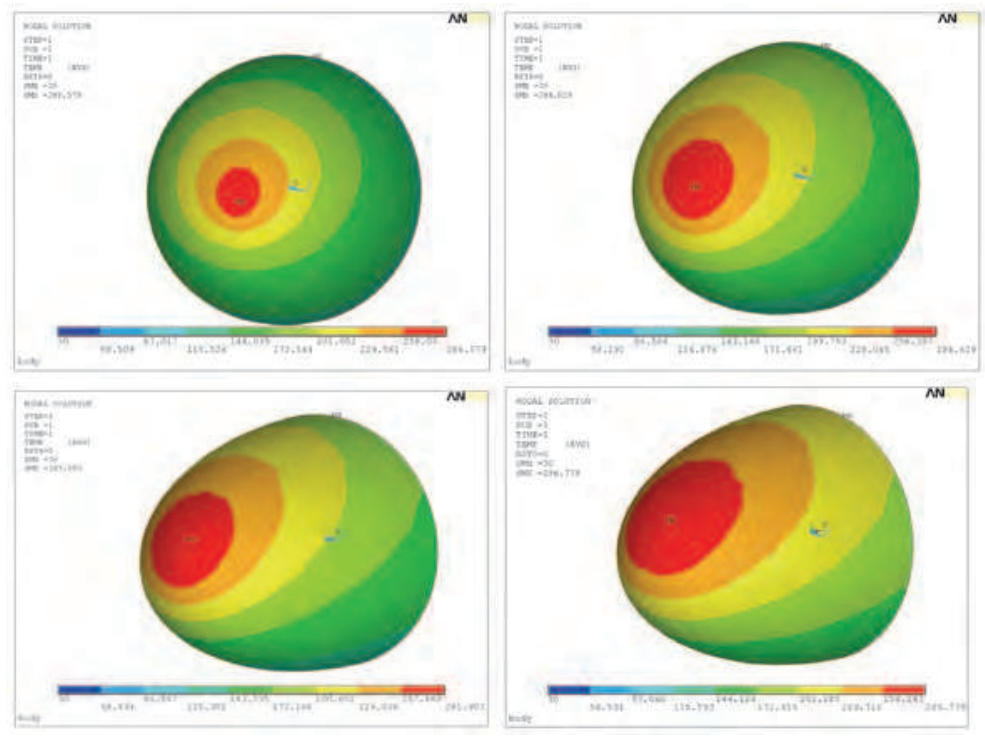

Fig. 34. Conformal dome temperature

Through the equilant stress simulation, the conformal dome's SEQV figure is got as shown in figure 35.

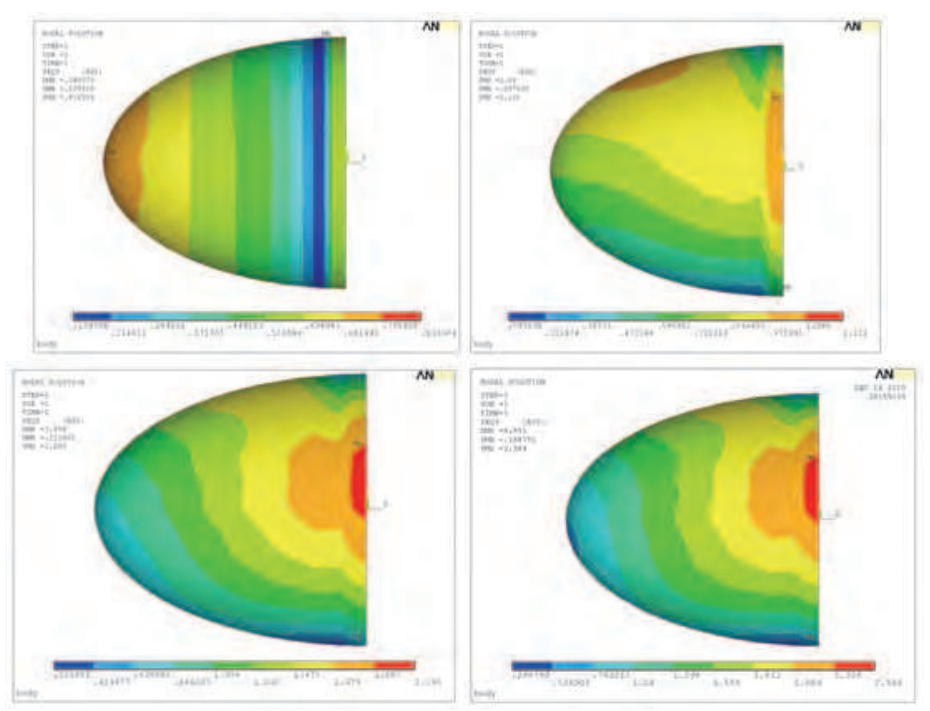

Fig. 35. Conformal dome equivalent stress simulation 
These stresses caused by aerodynamic load make the dome's shape change, and the some shape's change will bring the seeker's optical system additional aberrations. For example, the change of conformal dome's shape at $2.5 \mathrm{Ma}$ speed $0^{\circ}$ attack angle is put in optical design software ZEMAX. The MTF change is shown in figure 36. The left figure is orginal MTF of conformal optical system, and the right one is the MTF after dome's shape change. The spot diagram comparison is shown in figure 37.

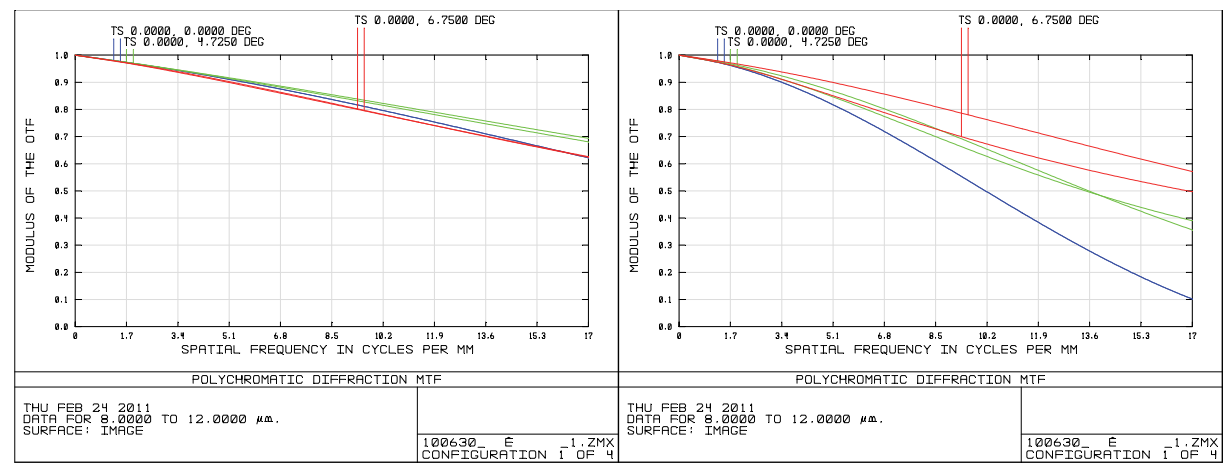

Fig. 36. Conformal optical system MTF comparison

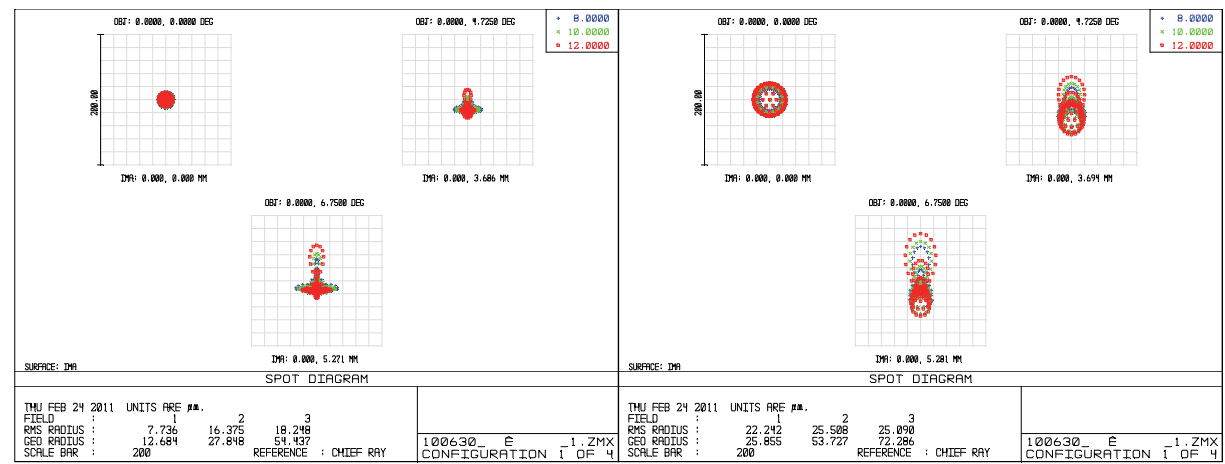

Fig. 37. Conformal optical system spot diagram comparison

\section{Conclusion}

In this chapter, two different kind of wind tunnel has been done. The first wind tunnel experiment is about spherical dome. The experiment is done from $0.4 \mathrm{Ma}$ to $3 \mathrm{Ma}$ with the attack angle from $0^{\circ}$ to $10^{\circ}$. The comparison of force and shock wave figure ensure the reliability of spherical dome wind tunnel experiment. The data of wind tunnel experiment is used to study how aerodynamic affects the dome. The conclusion is the shock wave and the outflow can be considered as one or several air lenses which loacts before the dome. So when the missile flies, the ouflow of the dome will add aberration to the optical system. The second wind tunnel experiment is about conformal dome which is foucs topic now. This wind tunnel experiment is divided into two parts: pressure measurement wind tunnel 
experiment and temperature measurement wind tunnel experiment. Besides, CFD simulation is used when wind tunnel data is not enough. The comparison of the pressure of conformal dome's sureface shows that the CFD simulation has a very high accuracy. The pressure and temperature data is the input file of conformal dome FEA simulation which is used to value how the shape and temperature change. After simulation, the shape change data is put in optical design software, and the MTF and spot diagram of optical system goes down.

\section{References}

K. V. Ravi. Diamond Technology for Endo-KEW Seeker Windows. AIAA, 92-2801.

Scott B., Mike B., \& Scott D.. Recent Development in Finishing of Deep Concave, Aspheric, and Plano Surfaces Utilizing the UltraForm 5-axes Computer Controlled. SPIE, 2009, Vol.7302, 73020U.

Paul E. M., Jon F., \& Greg F.. High precision metrology of domes and aspheric optics. SPIE, 2005, Vol.5786, 112-121.

William P. K., Matthew B. D., \& Robert S. L.. Measurement results for time-delayed source interferometers for windows, hemispherical domes, and tangent ogives. SPIE, 2009, Vol.7302, 73020R.

Thomas J. H., W. Lance R., \& Leslie G.. A technique for transient thermal testing of thick structures. SPIE, 1997, Vol.3151, 73-91.

Claude A. K.. How Missile Windows Degrade the Noise-Equivalent Irradiance of Infrared Seeker Systems. SPIE, 1994, Vol.2286, 458-470.

Zhao N., Chang J., \& Sun Z.. Summarize of Conformal Optics. SPIE, 2007, Vol.6624, 66241N.

Juan M. Ceniceros, David A. Nahrstedt, \& Y-C Hsia, et al.. Wind Tunnel Validation of a CFD-Based Aero-Optics Model. AIAA, 2007-4011.

Girimaji S. S., Abdol-Hamid K. S.. Partially-averaged Navier-Stokes Model for Turbulence: Implementation and Validation. AIAA, 2005-502.

Tosh A., Frendi A., \& Girimaji S.. Partially Averaged Navier Stokes: A New Turbulence Model for Unsteady Flows with Application to Acoustics. 11\# AIAA/CEAS Aeroacoustics Conf, Monterey, CA, May 23-25, 2005. http://www.bia701.co/html/e17fd0602.htm

M Born \& E. Wolf. Principles of Optics. Cambridge U. Press, 1999, 92-93.

G. Havener. Optical Wavefront Variance: a Study on Analytic Modes in Use Today. AIAA, 92-0654.

G. C. Li. Aero-optics. National Defense Industry Press, 2006.

Xingqiao Ai, Xin Zhang, \& Zhenhai Jiang, et al.. Modulation transfer function in seeker camera limits resulting from missile flutter caused by aerodynamic force. ICIMA, 2010, 146-151.

Huhai Jiang, Qun Wei, Hongguang Jia. Analysis of impact of gyroscope synthetical error on an electric-optical stabilized control system. BMEI, 2010, 2623-2625.

Qun Wei, Hongguang Jia, Ming Xuan. Equivalent lenses of supersonic seeker's outflow refractive index field obtained by simulation and experiment. SPIE, 2009, Vol.7156, 71561Q.

Wei Qun, Bai Yang, \& Liu Hui. Optimized design of the inside surface of supersonic missile's elliptical dome. SPIE, 2009, Vol.7384, 73840E. 
Ai Xingqiao, Wei qun, Jia Hongguang. Dome design and coupled thermal-mechanical analysis of supersonic missile. SPIE, 2009, Vol.7506, 75061Q.

Wei Qun, Zhang Xin, \& Jia Hongguang. The design of missile's dome that fits both optical and aeordynamic needs. SPTE, 2010, Vol.7659, 76590F.

Jiang Zhenhai, Zhang Xin, \& Ai Xingqiao. Gimbal displacement errors analysis on an electro-optical seeker. SPIE, 2010, Vol.7849, 784924.

Wei Qun, Ai Xingqiao, \& Jiang Huhai. The optimize design of supersonic seeker's dome. Optics and Precision Engineering, Vol.18, No.2, 384-389. 


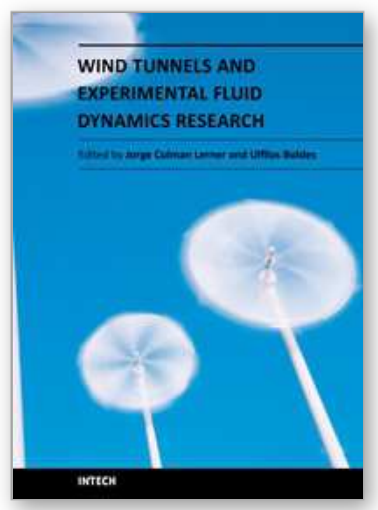

\author{
Wind Tunnels and Experimental Fluid Dynamics Research \\ Edited by Prof. Jorge Colman Lerner
}

ISBN 978-953-307-623-2

Hard cover, 709 pages

Publisher InTech

Published online 27, July, 2011

Published in print edition July, 2011

The book â€œWind Tunnels and Experimental Fluid Dynamics Researchâ€ is comprised of 33 chapters divided in five sections. The first 12 chapters discuss wind tunnel facilities and experiments in incompressible flow, while the next seven chapters deal with building dynamics, flow control and fluid mechanics. Third section of the book is dedicated to chapters discussing aerodynamic field measurements and real full scale analysis (chapters 20-22). Chapters in the last two sections deal with turbulent structure analysis (chapters 23-25) and wind tunnels in compressible flow (chapters 26-33). Contributions from a large number of international experts make this publication a highly valuable resource in wind tunnels and fluid dynamics field of research.

\title{
How to reference
}

In order to correctly reference this scholarly work, feel free to copy and paste the following:

Qun Wei, Hongguang Jia, Ming Xuan and Zhenhai Jiang (2011). Wind Tunnel Experiments for Supersonic Optical-Electrical Seeker's Dome Design, Wind Tunnels and Experimental Fluid Dynamics Research, Prof. Jorge Colman Lerner (Ed.), ISBN: 978-953-307-623-2, InTech, Available from:

http://www.intechopen.com/books/wind-tunnels-and-experimental-fluid-dynamics-research/wind-tunnelexperiments-for-supersonic-optical-electrical-seeker-s-dome-design

\section{INTECH}

open science | open minds

\section{InTech Europe}

University Campus STeP Ri

Slavka Krautzeka 83/A

51000 Rijeka, Croatia

Phone: +385 (51) 770447

Fax: +385 (51) 686166

www.intechopen.com

\section{InTech China}

Unit 405, Office Block, Hotel Equatorial Shanghai

No.65, Yan An Road (West), Shanghai, 200040, China

中国上海市延安西路65号上海国际贵都大饭店办公楼 405 单元

Phone: +86-21-62489820

Fax: $+86-21-62489821$ 
(C) 2011 The Author(s). Licensee IntechOpen. This chapter is distributed under the terms of the Creative Commons Attribution-NonCommercialShareAlike-3.0 License, which permits use, distribution and reproduction for non-commercial purposes, provided the original is properly cited and derivative works building on this content are distributed under the same license. 